\title{
Heat and energy fluxes in the convective cell behind a cold front
}

\author{
S. Ivanov and J. Palamarchuk \\ Department of Meteorology and Forecasting, Environmental University, 65016 Odessa, Ukraine \\ Received: 15 October 2009 - Revised: 8 March 2010 - Accepted: 11 March 2010 - Published: 16 March 2010
}

\begin{abstract}
High resolution model simulations are used to estimate heat fluxes and energy conversion in the convective cell developing behind a cold front. It is found that the model is able to simulate rapid temperature changes in the low troposphere up to $1^{\circ} \mathrm{C}$ for a time period of a few minutes due to latent heat release as well as horizontal acceleration up to $5 \mathrm{~m} / \mathrm{s}$ at the top of convective circulation. Numerical experiments have also shown sensitivity of fine resolution simulations to parameterizations used for the description of a largescale flow.
\end{abstract}

\section{Introduction}

Numerous studies (Fuelberg and Scoggings, 1978; Robertson and Smith, 1980; Weusthoff and Hauf, 2008) have shown that energy sources and sinks demonstrate considerable spatial variation on mesoscales within individual synoptic patterns. Such inhomogeneity is often observed under postfrontal conditions, i.e. in the cold air mass over the warm surface behind a cold front, and associated with post-frontal convection. The radar network allows tracking of the life cycle and spatial structure of individual convective cells and clusters (Pierce et al., 2000; Weusthoff and Hauf, 2008). The combination of satellite and radar data with analysis charts provide the opportunity to investigate the interactions between various mesoscale structures like upright and slantwise convection including the effects of evaporation in the dry slot as well as the role of inertia-gravity waves and conditional symmetric instability in triggering/organizing the convective bands and multiple cloud head structures (Browning, 2005). However, high resolution mesoscale modelling is still required to estimate and better understand energy conversions and their relative importance on those scales.

Correspondence to: $\mathrm{S}$. Ivanov

(svvivo@te.net.ua)
This work examines a post-frontal convective cell behind a cold front. In particular, the energy conversion between kinetic and potential parts along with heat and moment fluxes are mainly overviewed on the base of high-resolution numerical modelling. In Sect. 2 of the paper, the synoptic pattern and associated mesoscale cloud systems are described in general terms. Section 3 includes the configuration of high resolution numerical experiments with the MM5 model. Heat fluxes within a post-frontal convective circulation are estimated in Sect. 4. The upscale energy cascade from convective ascent to the large-scale flow is also given in this section. Section 5 shows the sensitivity of results to the physical formulation of the model.

\section{Synoptic discussion}

The case-study presents a strong interaction area between cyclones that originate over the Atlantic and the ridge of subtropical origin over Western Europe on 18-20 March 2002 (Fig. 1). Invasion of warm air from the south up to eastern Scandinavia has reinforced the multi-center depression over the polar region. The latter, in its turn, has an impact on the eastward moving Atlantic cyclone, which occupied Northern and Western Europe. The cyclone stretched throughout the entire troposphere and moved to the north-east with surface pressure dropping down to $983 \mathrm{hPa}$ in the core. The frontal systems associated with the low pressure pattern brought severe weather conditions to the region with storms and heavy precipitation.

Mesoscale convective systems (MCSs) behind the frontal line were observed by the radar network and conventional surface measurements. In particular, the X-band radar located in Bonn (for a quick reference, see here: http:// www.meteo.uni-bonn.de/forschung/gruppen/radar/) has revealed two types of intensive MCSs, whose impact on local weather conditions extends over most of Western Germany during the period from 16:00 UTC 18 March to 01:00 UTC 19 March 2002 (Fig. 2). These systems were continuously developing on a background of upper-level

Published by Copernicus Publications on behalf of the European Geosciences Union. 


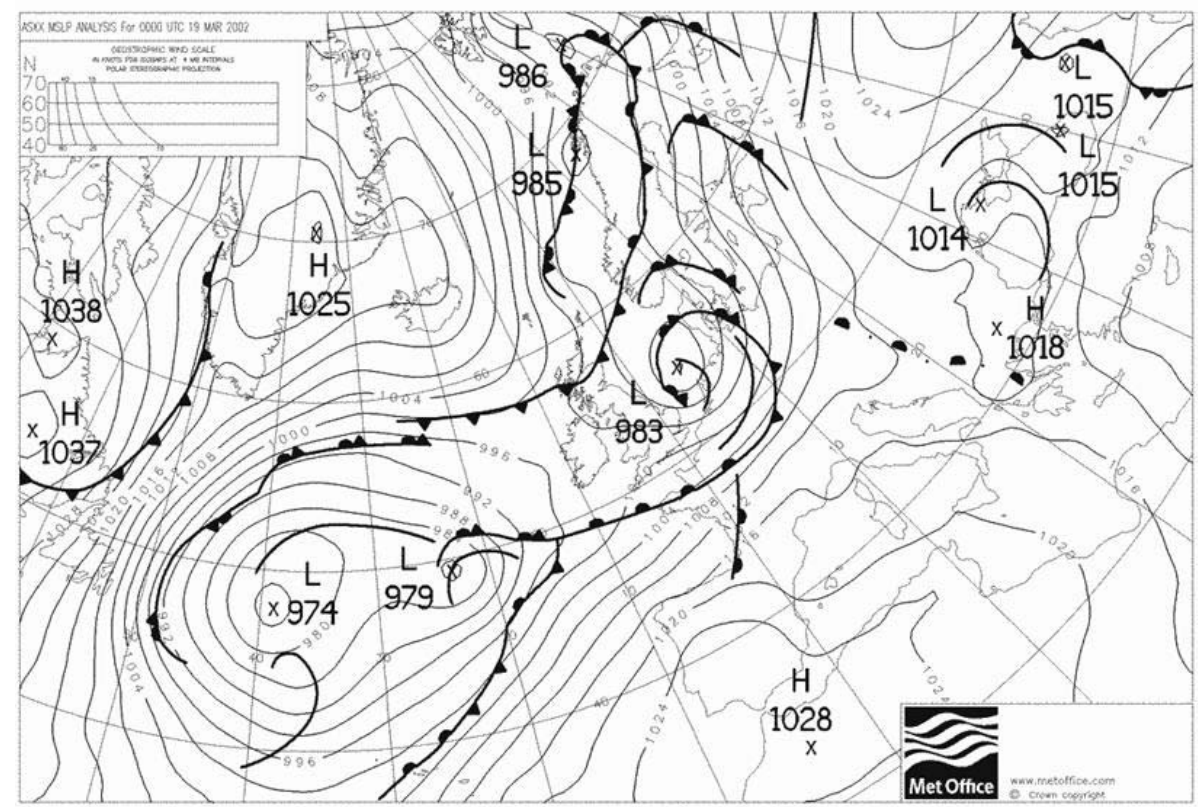

Fig. 1. The synoptic pattern developing on 00:00 UTC 19 March 2002 (from UKMO chart).
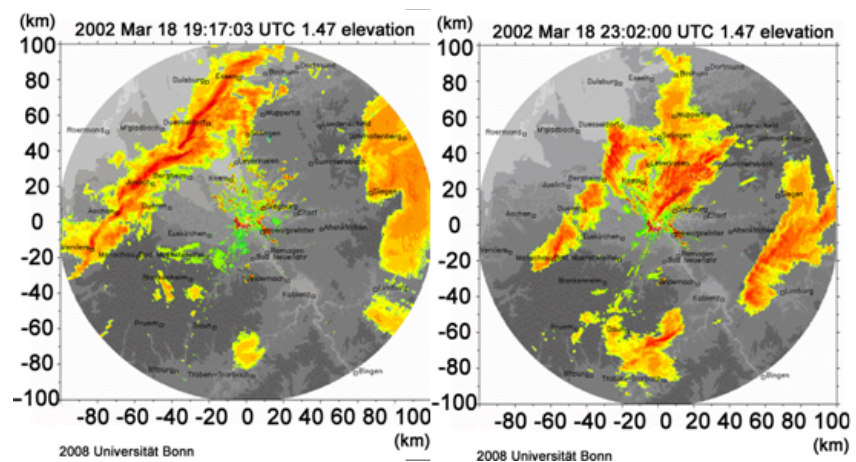

Fig. 2. Radar of (a) convective and stratiform clouds on a cold front (19:17 UTC 18 March 2002), (b) cloud band of the instability line (23:02 UTC 18 March 2002). (for a quick reference, see here: http://www.meteo.uni-bonn.de/forschung/gruppen/radar/).

atmospheric disturbances and moving with a mean rate of about of $50 \mathrm{~km} / \mathrm{h}$. The first type represents a combination of convective and stratiform clouds on the cold front. Radar reflectivity shows multi-cell convective pattern of intensive precipitation on a background of weak precipitation from stratiform clouds. The second MCS type has a form of the narrow convective cloud bands, often called as the instability line, which followed approximately $2.5 \mathrm{~h}$ later at a distance of $150 \mathrm{~km}$ behind the major frontal cloud system. The substantial horizontal gradient in temperature within relatively homogeneous cool air allows us to associate this band of convective activity with the secondary cold front.

\section{High resolution model configuration}

Bearing in mind that the focus is on sub-synoptical scale features like MCSs and their interactions with the large scale flow through heat fluxes and energy conversion, high resolution model experiments were performed. The NCAR Mesoscale Model (MM5, see Grell et al., 1994) with 3 nested domains and 40 vertical levels is used. The outer D1 domain of the $9 \mathrm{~km}$ resolution with $199 \times 199$ grid nodes covers the Europe and North Atlantic regions, where the evolution of the large scale flow along with cyclones and fronts occurs. The D2 domain of the $3 \mathrm{~km}$ resolution is used as auxiliary to ensure the interaction between D1 and the fine resolution $(1 \mathrm{~km})$ D3 domain. The latter domain of a size of $103 \times 103$ nodes $(\mathrm{km})$ overlays the area covered by the radar data. The vertical resolution in the boundary layer is equal to about $50 \mathrm{~m}$ and gradually increases to $500 \mathrm{~m}$ near the upper boundary at $10 \mathrm{hPa}$.

The atmospheric state developing on the fine resolution D3 domain is the one which is mainly considered in this paper. The reference experiment providing the optimal mesoscale features has been run with the high-resolution Blackadar scheme for the planetary boundary layer (PBL) and Reisner scheme for microphysics processes, while convection has been explicitly simulated on the D3 domain. Note that the radiation parameterization is normally not used for daughter domains in the MM5 model.

Series of experiments with different parameterizations on all domains have been run in order to light up the sensitivity of results to model formulations. In particular, the Eta and MRF schemes (Grell et al., 1994) for the boundary layer, and 

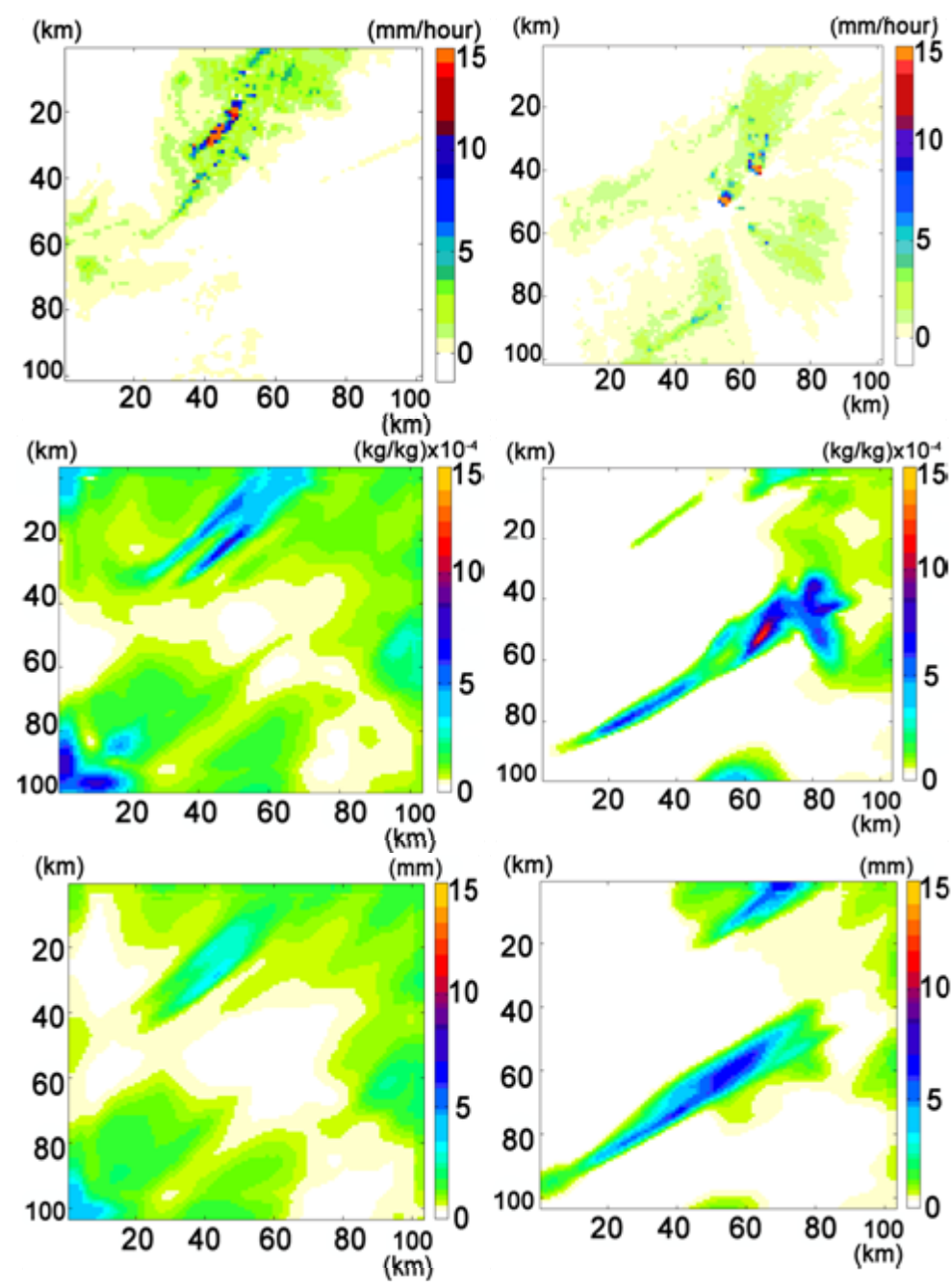

Fig. 3. Radar images (top) and model fields of rain water (middle) and ground precipitation (bottom) at 16:46 UTC (left) and 21:21 UTC (right) 18 March 2002.

the mixed-phase of Reisner and Goddard schemes for microphysics were explored for the D1 and D2 domains. Explicit cumulus production and the Grell parameterization have also been used to simulate convection processes on the D1 domain.

\section{Heat fluxes and upscale energy cascade in the convective circulation}

Large-scale heat and moisture fluxes are properly simulated in current models and justified by observations. In difference, spatial and temporal behaviour of mesoscale processes associated, in particular, with convection is still under investigations (Bechtold et al., 2001; Kuell et al., 2007). Even with a horizontal grid resolution of order of about $10 \mathrm{~km}$, models require exploring the convective and boundary layer parameterization schemes. These schemes should properly account the stability of layers, vertical redistribution of mass, moisture and energy under prescribed conditions, saturation rate in convection processes and other factors. Fine resolution models allow obtaining many of those characteristics due to explicit simulations of convective processes, although results may still suffer by unconfined description of processes on smaller scales.

In the present paper both horizontal and vertical distribution of atmospheric variables along with energy estimations within a single MCS are investigated. Precipitation patterns observed by radar are used for comparison with the model results (Fig. 3). As it can be seen, the radar images and rain water field simulated in the model are not identical. There are several well-known reasons for it, among of them both radar and model deficiencies (Austin, 1987; Ivanov and Palamarchuk, 2007). In particular, radar provides reflectivity measurements, which requires the subsequent conversion to water content. That transformation is non-linear and 


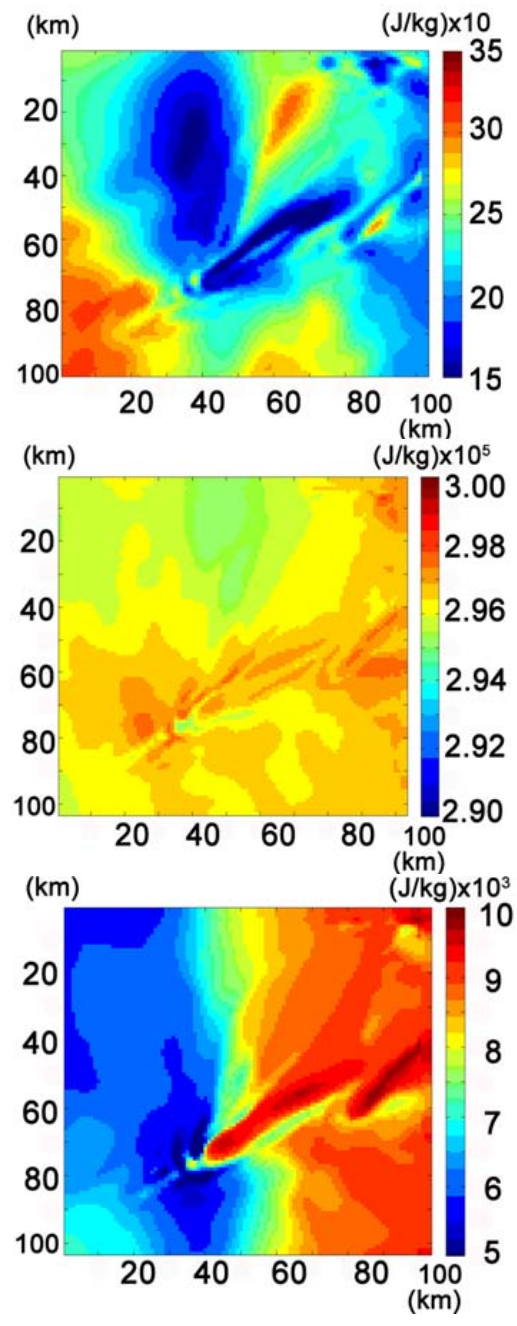

Fig. 4. Spatial distribution of kinetic energy (top), and turbulent (middle) and latent (bottom) heat fluxes at the $700 \mathrm{hPa}$ level in the model.

sensitive to the drop size distribution relation. Additionally, radar measures water content in the atmosphere that is not equal to the amount of precipitation on the surface due to evaporation of rain water in the atmosphere. On the other hand, models often mispredict the amount and location of precipitation because of deficiencies in their formulations.

Regarding this study, the comparison of the modelled and radar images on 18 March 2002 confirms the model's ability in producing mesoscale cloud-precipitation features. In particular, the position and general configuration of main precipitation cells in both images match each other. The modelled rain water content and the radar reflectivity converted to precipitation rate are also in a reasonable agreement, although a certain phase error is present.

The first type of MCSs described in Sect. 2, namely, the convective cell pattern behind a cold front is described here in terms of energy and heat fluxes. Figure 4 reflects the spa-
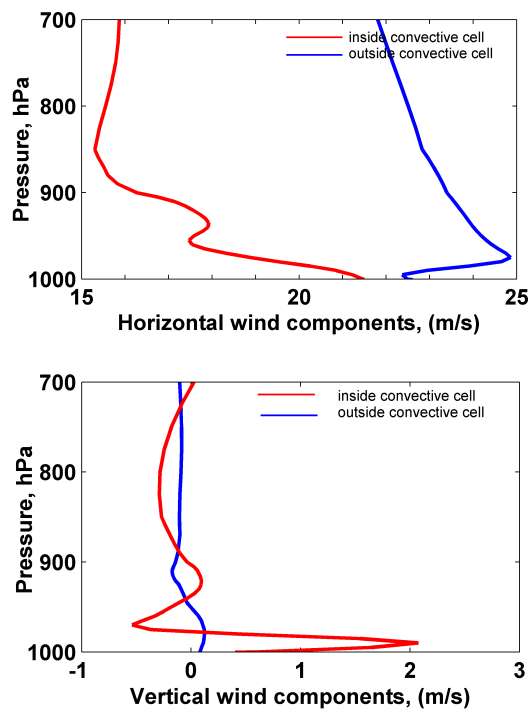

Fig. 5. Vertical profiles of the horizontal (top) and vertical (bottom) wind components within the MCS (red) and surrounding air (blue).

tial distribution of kinetic energy, and turbulent and latent heat fluxes at the $700 \mathrm{hPa}$ level. Those forms clearly show the MCS of a size of about $10-20 \mathrm{~km}$. Moreover, potential energy after spatial low-pass filtering, which removes general pressure tendency in south-eastward direction, also shows mesoscale features of the same and smaller sizes (not shown). The latter perturbations are stationary and associated with gravity waves of orographic origin, while the larger structure coincides with the sub-synoptical atmospheric pattern.

The MCS owns a minimum of kinetic energy, while available potential energy (APE) and latent heat flux associated with water phase conversion are the largest over the domain. The values vary with the altitude, but the ratio of about two versus the background keeps throughout the low and middle troposphere. For example, the largest differences for wind speed are observed in the layer between 925 to $700 \mathrm{hPa}$ levels, where this value sharply increases from $15 \mathrm{~m} / \mathrm{s}$ in the core to about $25 \mathrm{~m} / \mathrm{s}$ toward the edges (Fig. 5). The vertical wind component agrees well with such kinetic distribution. In particular, ascent motions are the fastest in the core with vertical speed peaking at $2 \mathrm{~m} / \mathrm{s}$ and descent occurs on the boundaries with the vertical speed of about of $0.5-1 \mathrm{~m} / \mathrm{s}$. The 3D motion in terms of streamlines is shown in Fig. 6 . The main feature of this figure is the strong and narrow ascending flow in the 950-700 $\mathrm{hPa}$ layer whose horizontal dimension is less than $10 \mathrm{~km}$. This ascent results in acceleration of the large-scale flow at the top of the layer.

Kinematical patterns are accompanied by thermodynamic processes. Figure 7 shows latent heat fluxes between the MCS and surrounding air, in particular, fluxes associated with the rain formation (LeR), cloud water condensation $(\mathrm{LeCW})$ and snow sublimation (LeSN). The first two 


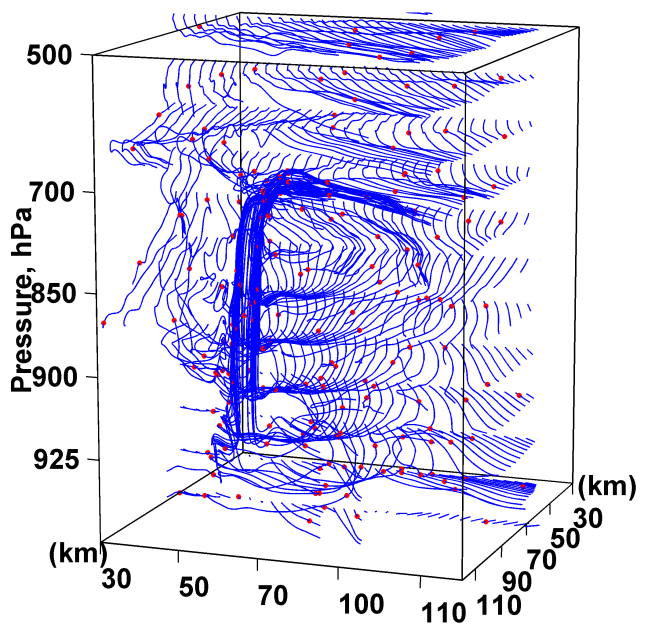

Fig. 6. The 3D streamlines within the MCS.

components are dominant. The LeR flux has a quasi-bipolar form, in which the negative pole is smaller in size and value. For example, the positive LeR flux in the cell core reaches the value of about $250-300 \mathrm{~J} / \mathrm{kg}$, while negative flux located on a warm side of the MCS is smaller than $100 \mathrm{~J} / \mathrm{kg}$. The condensation is recognized by the larger amount of rain water content inside the cell as well as a higher temperature area (not shown), which increased by $1-1.5^{\circ} \mathrm{C}$ due to latent heat release.

On the contrary, for the LeCW fluxes the negative values are comparable with the positive ones reaching $1000 \mathrm{~J} / \mathrm{kg}$. Evaporation from cloud and precipitation lead to the formation of narrow bands of lower temperatures of about $1.5-2{ }^{\circ} \mathrm{C}$ compared to the background value.

Another interesting issue of the energy conversion on mesoscales is the transfer of APE to kinetic energy. This is actually an upscale energy cascade, associated with convective circulation involved into the large-scale flow and accelerating the latter. Given that the orders of kinetic energy of a large-scale flow and APE in convective processes are considerably different, an obvious approach is to consider the relative velocity field. This allows us not only to obtain mesoscale kinetic features of the flow, but also detect the quasi-stationary waves of orographic origin, which are discussed later. So, the upscale cascade releases mainly on the top of the MCS, while convective APE accumulates in the layer between the surface and $700 \mathrm{hPa}$ level.

Maximum value of increasing kinetic energy within the MCS is equal to about $50 \mathrm{~J} / \mathrm{kg}$ during $5 \mathrm{~min}$ (the time between model outputs) (Fig. 8), which corresponds to acceleration of about $5 \mathrm{~m} / \mathrm{s}$ during such a short period. Such estimation agrees well with observations of frontal gusts (May, 1998) and proves the ability of the model in simulating the complexity of non-linear mesoscale processes. Above the $700 \mathrm{hPa}$ level, kinetic energy of the flow increases less rapidly or even drops. Thus, the major non-linear processes

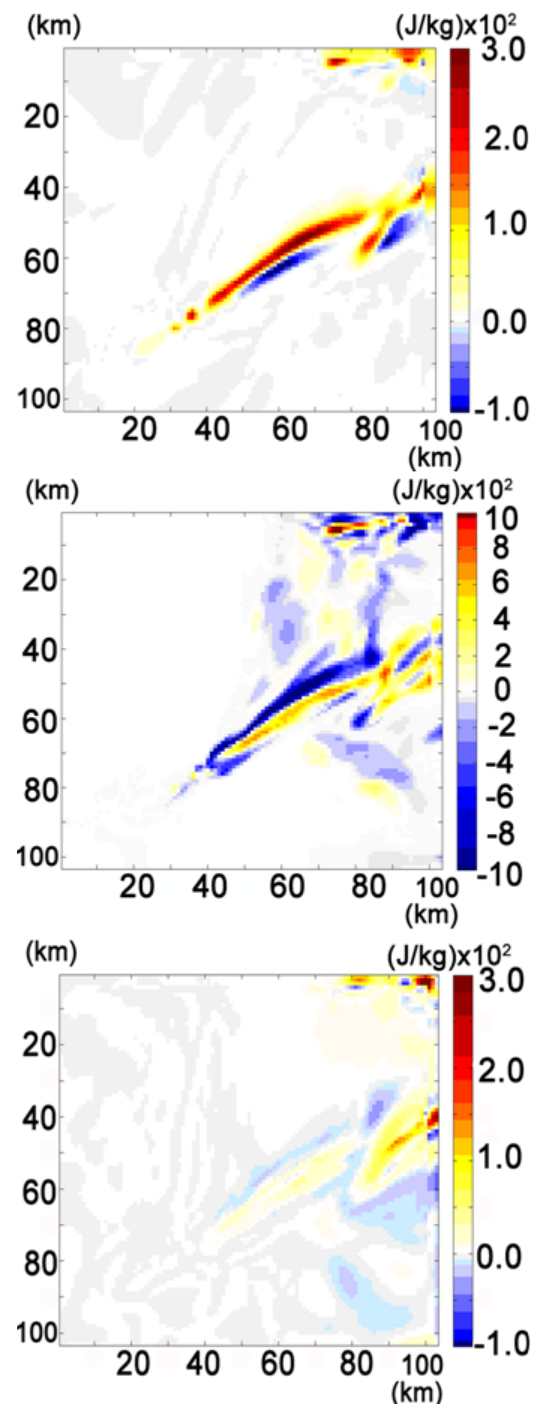

Fig. 7. Components of latent heat flux due to conversions of water phase: rain formation (top), cloud water condensation (middle), snow sublimation (bottom).

associated with energy transfers occur in the lower troposphere below $700 \mathrm{hPa}$.

Apart from the main subject of the paper, it is worth to note that the spatial variations of kinetic energy associated with quasi-stationary orographic waves reach values as large as $20-30 \mathrm{~J} / \mathrm{kg}$, which is of the same order as in the convective cell, although twice less. Those waves are seen in both the relative velocity and low-pass spatial filtered geopotential fields (Fig. 8) as background in a form of stationary ridges and troughs (the yellow-green and blue colors, correspondingly). The flow speeds up and down with about $2 \mathrm{~m} / \mathrm{s}$ over a top and in trough, correspondingly. Fig. 9 also confirms the close relation between kinetic energy and local gradients in the geopotential field, for which the correlation is equal to about 0.85 . 


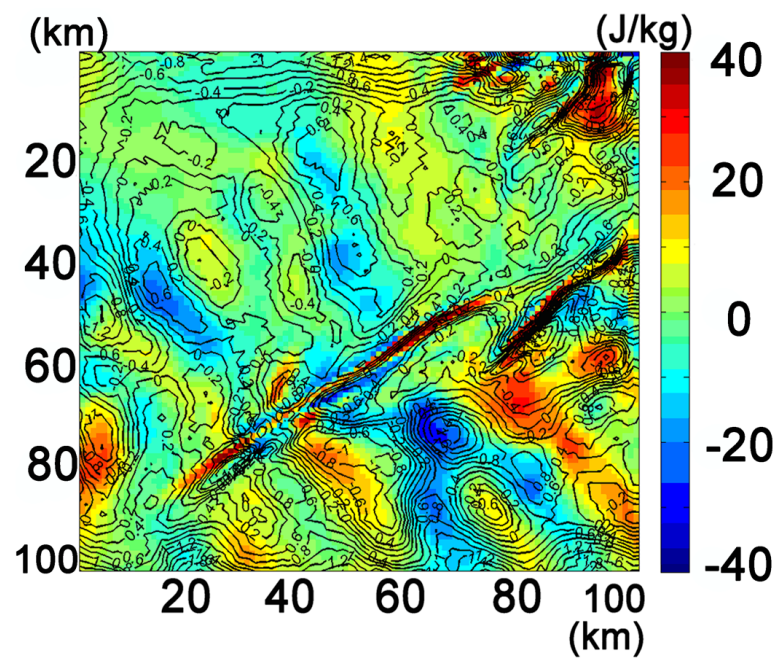

Fig. 8. Changes of kinetic energy in the relative velocity field (in color bar) and spatial low-pass filtered geopotential field (in isopleths).

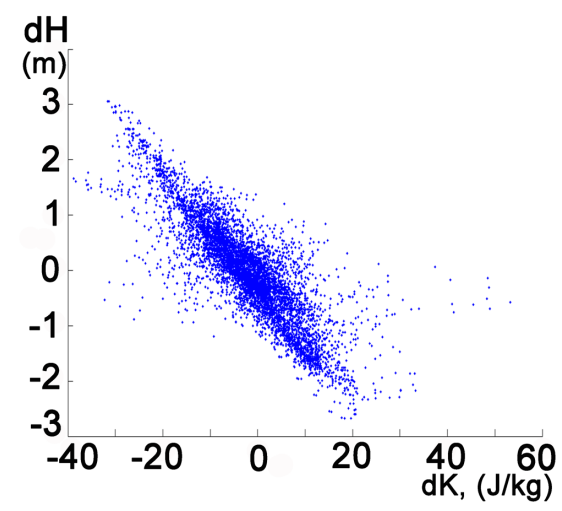

Fig. 9. The relation between kinetic energy changes and local gradients in the geopotential field.

\section{Sensitivity of mesoscale simulations to parameterisation schemes}

The above results have been obtained with the parameterisation schemes described in Sect. 3. That set of schemes provides realistic behaviour of mesoscale features and can be considered as the acceptable one, even though there are some discrepancies with radar images. The other parameterizations recommended for high resolution (less than $10 \mathrm{~km}$ ) simulations (Grell et al., 1994) are also explored in this study. This work does not pursue the comprehensive study of issues of different parameterizations, but rather light up two aspects. The first and general aspect is that a result depends on a parameterization choice even for those schemes which are recommended for the resolution employed. The second that a result obtained with the same parameterization is sensitive to the model resolution.
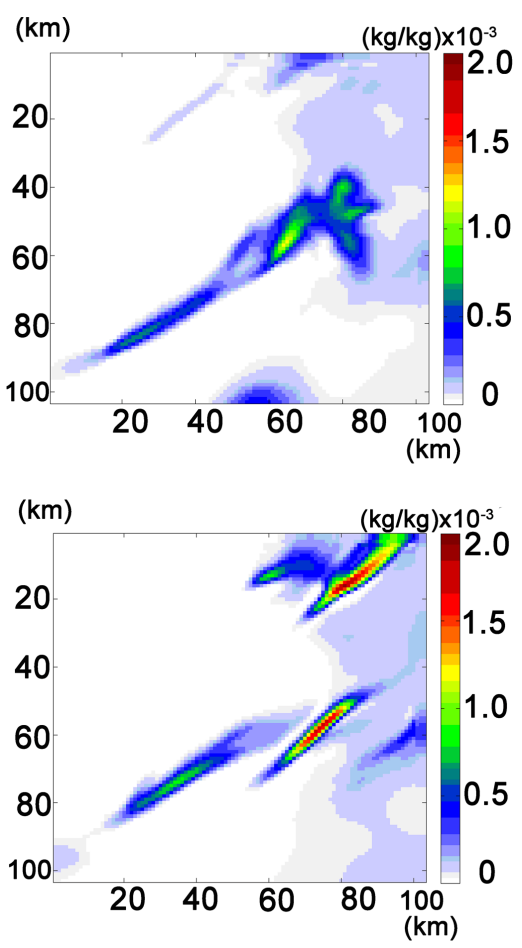

Fig. 10. Rain water content simulated on the fine resolution D3 domain with the explicit convection description (top) and Grell parameterization (bottom) on the coarse resolution domain D1 domain.

In particular, Fig. 10 shows the rain water fields obtained in two runs. The difference between those model configurations is only in simulating the convection processes on the coarse resolution D1 domain, where large scale flow is simulated, while the same configurations have been used on the fine resolution D3 domain. The first run has explored explicit description of the convective processes, and the second includes the Grell scheme (Grell et al., 1994). One can see that the second run does not provide the required amount of large scale preconditions for the rain water content, which results in underestimated precipitation compared to the radar images. The reasons for it may lie in specific features of the Grell parameterization. The scheme considers a convective process as two steady-state circulations caused by the updraft and downdraft. There is no direct mixing between the clouds and surrounding air, except at the top and the bottom of the circulations. Mass flux is constant with height, and there is no entrainment or detrainment along the cloud edges. Additionally, the conception does not take into consideration scale-separation. Thus, those assumptions numerically implemented in the scheme considerably underestimate water content involved into the convection.

The other example of the sensitivity of modelling results to parameterizations is given in Fig. 11. This shows the vertical profiles of cloud water content obtained in two runs. In both experiments the same parameterizations have been 

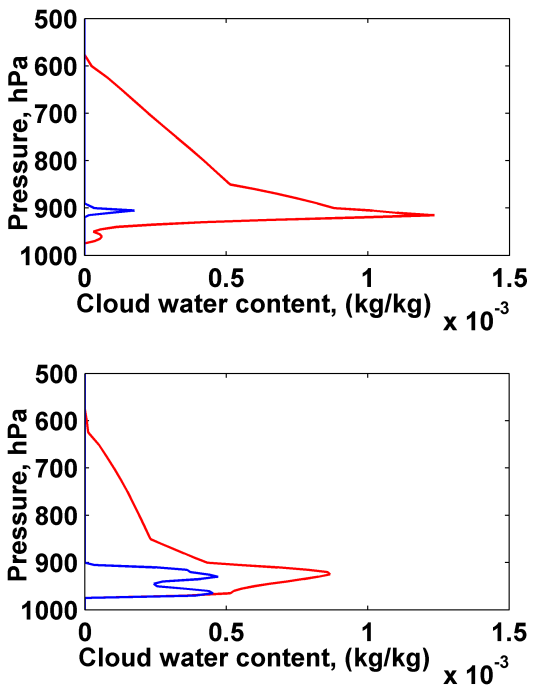

Fig. 11. Vertical profiles of the cloud water content in the simulations with MRF (top) and Blackadar (bottom) PBL schemes on the coarse resolution D1 domain inside the MCS (red) and in surrounding air (blue).

used on the fine resolution D3 domain, while the difference is in the use of a PBL scheme on the coarse resolution D1 domain. The first run has explored the MRF scheme based on the solution of turbulent kinetic energy equation (Janjic, 1994). The second experiment has employed the Blackadar high resolution model for PBL, which computes the vertical mixing of atmospheric variables for four different regimes of the stability (Grell et al., 1994). Even with the same vertical resolution, the latter configuration provides for the given case study the separation of the PBL in two sub-layers over the most part of the domain, which is clearly visible in major atmospheric variables such as temperature, wind velocity and humidity (not shown) as well as cloud water content distribution and rain formation. On the contrary, the MRF scheme caught only minor separation within the MCS and does not allow separation in the PBL over the rest of domain. This results in smearing of rain water content and underestimation of precipitation.

\section{Conclusions}

This paper presents the results obtained during simulations of an MCS developing behind a cold front. The focus is on the ability of the model to reproduce heat fluxes and energy conversion on mesoscales. Estimations have shown that air temperature on the convective cell periphery can change up to $1.5-2{ }^{\circ} \mathrm{C}$ during a short period due to condensation/evaporation in clouds and rain. The release of APE in convective process and conversion of it into kinetic energy may lead to up to $5 \mathrm{~m} / \mathrm{s}$ acceleration of the large-scale flow. Numerical experiments on a fine resolution domain have also shown the sensitivity of results to parameterization schemes employed on a coarse resolution domain, where the preconditioned large-scale flow is simulated.

The present case study reveals the potential of the model to realistically simulate dynamical evolution of a convective cell including energy transformations and will be further explored for investigating processes on mesoscales.

Acknowledgements. The MM5 modelling system used in this study has been provided by UCAR. The authors thank the Meteorological Institute, University of Bonn (MIUB) and Director Clemens Simmer for radar data provided. We also wish to thank the two referees for their constructive comments on the first version of this paper.

Edited by: S. C. Michaelides

Reviewed by: two anonymous referees

\section{References}

Austin, P. M.: Relation between measured radar reflectivity and surface rainfall, Mon. Weather Rev., 115, 1053-1070, 1987.

Bechtold, P., Bazile, E., Guichard, F., Mascard, P., and Richard, E.: A mass flux convection scheme for regional and global models, Q. J. Roy. Meteor. Soc., 127, 869-886, 2001.

Browning, K. A.: Observational synthesis of mesoscale structures within an explosively developing cyclone, Q. J. Roy. Meteor. Soc., 131, 603-623, 2005.

Fuelberg, H. E. and Scoggings, J. R.: Kinetic energy budgets during the life cycle of intense convective activity, Mon. Weather Rev., 106, 637-653, 1978.

Grell, G. A., Dudhia, J., and Stauffer, D. R.: A description of the fifth-generation Penn State/NCAR Mesoscale model (MM5), NCAR Technical Note, 398, 117 pp., 1994.

Ivanov, S. and Palamarchuk, J.: Fine-scale precipitation structure of a cold front and the problem of the representativeness error, Adv. Geosci., 10, 3-8, 2007, http://www.adv-geosci.net/10/3/2007/.

Janjic, Z. I.: The step-mountain eta coordinate model: Further development of the convection, viscous sublayer, and turbulent closure schemes, Mon. Weather Rev., 122, 927-945, 1994.

Kuell, V., Gassman, A., and Bott, A.: Towards a new hybrid cumulus parameterization scheme for use in non-hydrostatic weather prediction models, Q. J. Roy. Meteor. Soc., 133, 479-490, 2007.

May P.: Thermodynamic and vertical velocity structure of two gust fronts observed with a wind profiler/RASS during MCTEX, Mon. Weather Rev., 127, 1796-1807, 1998.

Pierce, C. E., Hardaker, P. J., Collier, C. G., and Haggett, C. M.: GANDOLF: A system for generating automated nowcasts of convective precipitation, Meteorol. Appl., 7, 341-360, 2000.

Robertson, F. R. and Smith, P. J.: The kinetic energy budgets of two severe storm producing extratropical cyclones, Mon. Weather Rev., 108, 127-143, 1980.

Weusthoff, T., Hauf, T.: The life cycle of convective-shower cells under post-frontal conditions, Q. J. Roy. Meteor. Soc.., 134, 841857, 2008. 